\title{
USULAN PENJADWALAN PRODUKSI BENANG MENGGUNAKAN METODE NEH DAN METODE ALGORITMA JOHNSON UNTUK MEMINIMASI WAKTU PRODUKSI DI PT. LAKSANA KURNIA MANDIRI SEJATI
}

\author{
Silvi Ariyanti ${ }^{1)}$, Adianto $^{2)}$ dan Ricky Miharja ${ }^{3)}$ \\ ${ }^{1)}$ Dosen Program Studi Teknik Industri Universitas Mercu Buana, Jakarta \\ ${ }^{2)}$ Dosen Program Studi Teknik Industri Universitas Tarumanagara, Jakarta \\ ${ }^{3)}$ Alumni Program Studi Teknik Industri Universitas Tarumanagara, Jakarta \\ e-mail: adianto@ft.untar.ac.id
}

\begin{abstract}
ABSTRAK
Banyaknya permintaan konsumen terhadap perusahaan, membuat produksi perusahaan mengalami keterlambatan untuk pengiriman. Pada saat ini kondisi penjadwalan di perusahaan belum dilakukan dengan optimal sehingga akan berpengaruh besar terhadap kinerja produksi perusahaan. Tujuan dari penelitian ini adalah untuk memimalkan waktu produksi atau makespan dengan metode NEH dan Algoritma Johnson yang akan berdampak pada berkurangnya lateness produksi yang dialami oleh perusahaan. Metode Algoritma Johnson mencari makespan dengan cara pengurutan dengan melalui beberapa iterasi, dengan mencari waktu terpendek dari produksi atau SPT (Shortest Processing Time), adapula metode penjadwalan NEH mencari makespan dengan melakukan pengurutan berdasarkan LPT (Longest Processing Time) terlebih dahulu kemudian memasukkan job berdasarkan pengurutan tersebut satu persatu, yang akan melalui beberapa iterasi. Pada penelitian ini ditemukan bahwa metode penjadwalan $\mathrm{NEH}$ adalah yang paling tepat karena paling banyak mengurangi makespan dan mengecilkan waktu lateness.
\end{abstract}

Kata kunci: Penjadwalan, Job, NEH, Algoritma Johnson.

\begin{abstract}
The number of consumer demand for the company, making the production of companies experiencing delays for delivery. At this time the condition of scheduling in the company has not been done optimally so it will have a big effect on the company's production performance. The purpose of this study is to minimize the time of production or makespan with $\mathrm{NEH}$ and Johnson algorithm that will affect the decrease of production lateness experienced by the company. The Algorithm Johnson method looks for the makepan by sorting through several iterations, by finding the shortest time of production or SPT (Shortest Processing Time), the NEH scheduling method for makespan by sequencing based on LPT (Longest Processing Time) are one by one, which will go through several iterations. In this study found that NEH scheduling method is the most appropriate because it reduces most makespan and minimizes latent time.
\end{abstract}

Keyword: Schedule, Job, NEH, Algorithm Johnson

\section{PENDAHULUAN}

Dalam memenuhi kebutuhan konsumen sesuai dengan due date yang telah ditentukan merupakan kewajiban yang harus dilakukan oleh perusahaan. Banyak sekali faktor yang menentukan untuk meminimalkan waktu produksi, salah satu yang terpenting adalah penjadwalan produksi secara optimal. Dalam suatu kegiatan produksi, untuk mendapatkan suatu hasil yang optimum, maka seluruh aktivitas-aktivitas produksi terlebih dahulu harus direncanakan dengan baik. Penjadwalan produksi yang telah dilakukan diharapkan dapat mengurangi idle (waktu tunggu) mesin agar dapat dilakukan produksi secara optimal.
PT. Laksana Kurnia Mandiri Sejati merupakan perusahaan yang memproduksi benang Acrylic. Perusahaan ini belum memiliki sistem penjadwalan yang optimal, dimana order yang masuk terlebih dahulu akan dikerjakan atau FCFS (First Come First Serve), dan orderan yang lain harus mengantri. Pada sistem ini juga belum memandang kuantiti orderan sehingga masih banyak penumpukan order. Dalam proses operasionalnya PT. Laksana Kurnia Mandiri Sejati belum melakukan penjadwalan produksi secara optimal di mana dalam hal ini masih mengalami keterlambatan dalam pengiriman produk pada beberapa konsumennya. Perumusan masalah yang akan 
dibahas pada penelitian ini adalah bagaimana menentukan penjadwalan produksi sehingga dapat mempersingkat atau mengoptimalkan waktu penyelesaian akhir (makespan) secara keseluruhan.

Berdasarkan permasalahan di atas,diperlukan adanya penjadwalan produksi serta proses pengerjaan job yang lebih efektif pelaksanaan aktivitas proses produksinya, namun tetap memperhatikan dan mengutamakan kualitas produk. Pada penelitian ini, menggunakan metode $\mathrm{NEH}$ (Nawaz, Enscore, and Ham) dan Algoritma Johnson sebagai pembanding dengan penjadwalan yang telah dilakukan oleh perusahaan. Dengan begitu, akan mendapatkan usulan metode yang sesuai dengan kebutuhan perusahaan untuk mempersingkat waktu produksi atau memperkecil makespan yang berdampak pada berkurangnya lateness pengiriman perusahaan ke konsumen.

\section{Penjadwalan Mesin Produksi}

Penjadwalan produksi merupakan salah satu tahap penting sebelum memulai kegiatan produksi. Waktu penyelesaian produk patut diperhitungkan oleh perusahaan. Keterlambatan produksi akan merugikan perusahaan karena dapat mengurangi kepercayaan pelanggan terhadap perusahaan. Bila produksi tersebut dapat diselesaikan terlalu awal dari due date yang telah ditetapkan, maka biaya simpan juga akan bertambah. Selain waktu penyelesaian produk, hal lain yang perlu diperhatikan oleh perusahaan adalah kebutuhan bahan baku, karena untuk dapat memproduksi suatu produk, maka bahan baku yang dibutuhkan harus sudah tersedia sebelum proses produksi dimulai. Dalam sebuah proses waktu pemesanan, dan jumlah persediaan bahan baku juga harus diperhitungkan. Dengan penjadwalan produksi yang baik tentunya mesin-mesin yang digunakan dapat dioperasikan sesuai dengan kapasitas yang dimiliki dan memperkecil kemungkinan timbulnya waktu yang tidak produktif dari mesin-mesin tersebut.

Dalam pembuatan jadwal harus diketahui lebih dahulu adalah kapasitas produksi mesin diukur berdasarkan bermacam-macam aturan yang dapat digunakan, diantaranya: (1) First
Come First Server (FCFS) dimana urutan pekerjaan diproses berdasarkan urutan order/pesanan yang masuk. (2) Shortest Processing Time (SPT) dimana urutan pekerjaan dipilih berdasarkan waktu proses yang paling singkat. (3) Longest Processing Time (LPT) dimana urutan pekerjaan dipilih berdasarkan waktu proses yang paling lama.

\section{Macam Penjadwalan Produksi}

Penjadwalan secara garis besar berdasarkan urutan proses produksinya dapat dibedakan dalam 2 macam yaitu pertama, Job Shop adalah pola alir dari $\mathrm{N}$ job melalui $\mathrm{M}$ mesin dengan pola aliran sembarang dan proses pengurutan pekerjaan untuk lintasan produk yang tidak beraturan. Penjadwalan pada proses produksi job shop salah satu ciri-cirinya adalah bentuk tata letak job shop biasanya digolongkan dari peralatan yang mempunyai fungsi yang mirip di suatu area [1]

Yang kedua, Flow Shop adalah proses penentuan urutan pekerjaan yang memiliki lintasan produk yang sama atau hampir sama. Pada dasarnya ada beberapa macam pola flow shop, antara lain: (a) Pure Flow Shop, Flow shop yang memiliki jalur produksi yang sama untuk semua tugas. Mesin disusun sesuai dengan alur proses yang ada dimana sebuah job diharuskan menjalani satu kali proses untuk tiap-tiap kondisi. Bentuk Pure Flow Sonata sistem.

\section{Penjadwalan Job pada Mesin}

Penetapan penjadwalan atau urutan job pada suatu produksi akan memberikan keuntungan: (1) Tenaga manusia dan mesin beserta kelengkapannya dapat digunakan seefektif mungkin. (2) Keterlambatan dan kemacetan dalam proses produksi dapat ditekan sekecil mungkin. (3) Penggunaan produksi dapat dilaksanakan dengan baik dengan cara membandingkan pelaksanaan produksi dan rencana urutan yang telah disusun. (4) Total waktu dan proses secara keseluruhan dapat dicari sampai seminimal mungkin. (5) Keseimbangan dari operasi dapat dilaksanakan dengan baik.

Penyelesaian dalam masalah penjadwalan ini dapat diklasifikasikan menurut jumlah mesin 
dan job yang dijadwalkan menjadi tiga macam yaitu: 1) Penjadwalan untuk N Jobs, 1 Mesin. 2) Penjadwalan untuk N Jobs, 2 Mesin. 3) Penjadwalan untuk N Jobs, M Mesin. Beberapa istilah umum yang digunakan dalam membahas masalah penjadwalan produksi [2]: 1) Waktu pengerjaan atau Processing Time (tij) adalah waktu yang dibutuhkan untuk menyelesaikan suatu pekerjaan/job ke-i pada mesin ke-j. 2) Waktu tunggu atau Waiting Time (Wij) adalah waktu yang dipergunakan oleh job/pekerjaan ke-i sebelum job tersebut diproses pada suatu mesin ke-j. 3) Batas akhir atau Due Date (di) adalah waktu yang diberikan setiap job/pekerjaan ke-i sebagai batas penyelesaian pekerjaan. 4) Allowance time (ai) adalah waktu longgar untuk proses diantara waktu ready/siap (ri) sampai dengan due date. 5) Waktu keseluruhan atau Completion time (Ci) adalah waktu yang diberikan pada setiap job/pekerjaan ke-I sebagai batas penyelesain pekerjaan. 6) Waktu keterlambatan atau Lateness Time (Li) adalah selisih dari completion time dikurangi due date. 7) Tardiness (Ti) adalah job yang terlambat diserahkan ke konsumen. 8) Earliness (Ei) adalah penyelesaian job lebih cepat dari batas waktu yang ditentukan. 9) Makespan (Ms) adalah waktu penyelesaian seluruh job pada shop.

\section{Penjadwalan N Jobs 2 Mesin - Algoritma Johnson}

Aturan Johnson adalah suatu aturan meminimumkan makespan dua mesin yang disusun paralel dan saat ini menjadi dasar teori penjadwalan [3]. Adapun prosedur Johnson memuat langkah: 1) Dapatkan waktu proses yang lebih kecil. Jika terdapat pada mesin A, tempatkan pekerjaan tersebut sebagai pekerjaan pertama pada mesin A. Jika terdapat pada mesin B tempatkan pekerjaan tersebut sebagai pekerjaan terakhir pada mesin B. 2) Pindahkan pekerjaan yang telah ditempatkan atau ditugaskan dan kembali ke langkah 1 . Jika semua pekerjaan telah selesai ditempatkan, maka diperoleh urutan yang optimal. Jika terdapat dua pekerjaan mempunyai waktu sama, pada mesin sama dimana waktu tersebut lebih kecil dari waktu pada mesin lain, maka pembagian penugasan untuk dua pekerjaan tersebut adalah sembarang.

Untuk permasalahan penjadwalan dengan mesin yang lebih dari dua buah, akan sulit dipecahkan dengan metode ini. Untuk mengatasinya, maka digunakan Metode Campbell yang merupakan pengembangan dari metode Johnson.

\section{Penjadwalan N Jobs M Machine}

Penjadwalan $\mathrm{N}$ job $\mathrm{M}$ mesin merupakan sebuah tipe static shop sequencing dimana $\mathrm{n}$ job harus diproses oleh m mesin. Seluruh pekerjaan tersebut diproses di awal periode pengerjaannya, serta tidak ada pekerjaanpekerjaan baru yang datang selama periode tersebut (static job arrival pattern). Juga pekerjaan-pekerjaan tersebut tidak diperbolehkan saling melewati urutan yang telah ditentukan (pekerjaan-pekerjaan bertahan pada posisi satu urutan yang sama).

Ada teknik secara heuristic mampu memberikan urutan yang baik / urutan yang optimal dalam menyelesaikan problem penjadwalan $\mathrm{N}$ jobs $\mathrm{M}$ machines yaitu metode algoritma Campbell [4]. Metode ini dipakai untuk menjadwalkan $\mathrm{N}$ job pada mesin yang lebih dari dua dan merupakan pengembangan dari metode Johnson. Dengan demikian metode Johnson dapat dipakai sebagai dasar perhitungan urutan job pada mesin.

\section{Metode Nawaz, Enscore, Ham (NEH)}

Metode Nawaz, Enscore, and Ham (NEH) ini dikembangkan oleh Muhammad Nawaz, E. Emory Enscore Jr, dan Inyong Ham pada tahun 1983.[5] "In a general flowshop, where all the jobs must past through all the machines in the same order, certain heuristic algorithms propose that the jobs with higher total process time should be given higher priority than the jobs with less total process time" yang artinya dalam penjadwalan flowshop secara umum, dimana semua job harus melewati semua mesin pada order yang sama. Algoritma heuristic ini mengusulkan bahwa job dengan total waktu proses yang lebih besar seharusnya diberikan prioritas yang lebih besar dari pada job dengan total waktu proses yang lebih kecil. 
Algoritma NEH mengasumsikan job yang memiliki total waktu proses untuk semua mesin yang lebih besar harus didahulukan dibanding job dengan total waktu proses yang lebih kecil. NEH menginisialisasikan urutan job secara descending berdasarkan total waktu proses tiap job-nya. Kemudian dilakukan proses partial squence, yaitu menentukan urutan terbaik dari setiap posisi job yang mungkin.

\section{Flowchart}

\section{METODOLOGI PENELITIAN}

Penelitian ini tentu memerlukan urutan pelaksanaan yang terencana dan terperinci agar penelitian dapat berjalan dengan baik. Dalam penelitian ini, pada awalnya dilakukan identifikasi masalah kemudian studi pustaka untuk mengetahui metode apa yang digunakan untuk menyelesaikan masalah tersebut, kemudian menentukan tujuan dari penelitian. Setelah itu dilakukan pengumpulan data dan pengolahan data menggunakan Metode NEH dan Algoritma Johnson's dari kedua metode tersebut dipilih metode yang terbaik untuk perbaikan produksi. Flowchart dapat dilihat pada Gambar 1.
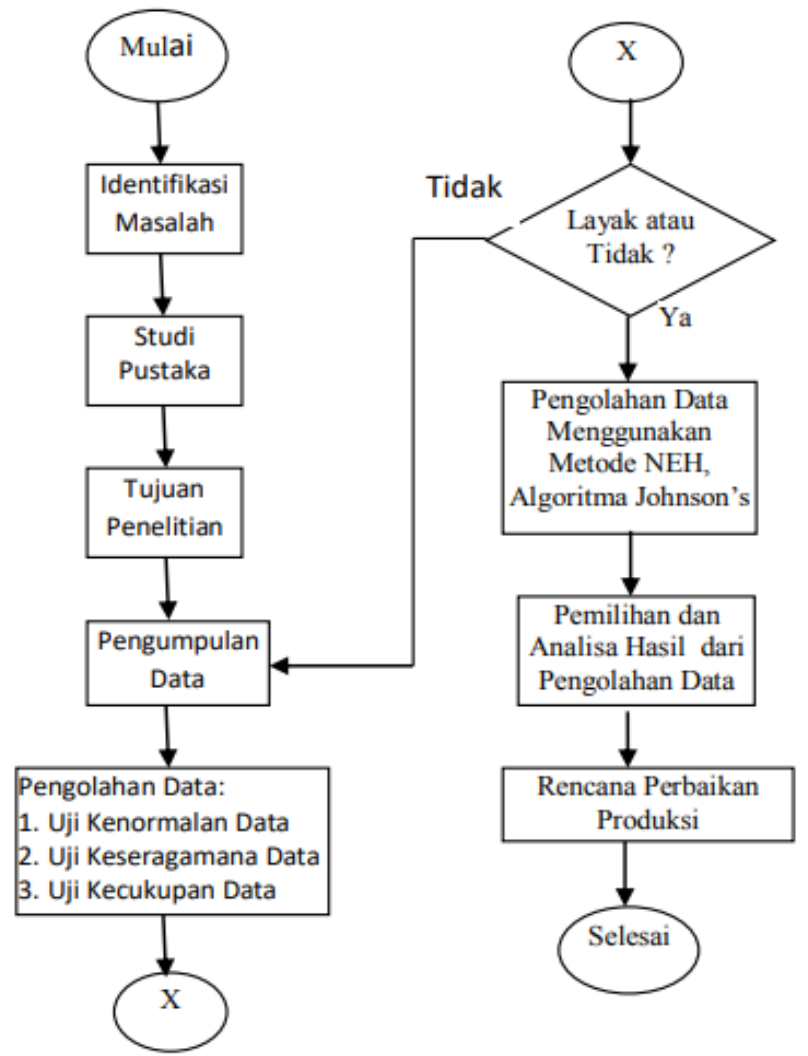

Gambar 1. Flowchart Penelitian

\section{Identifikasi dan Definisi Variabel}

Variabel-variabel yang berhubungan dengan permasalahan, yaitu sebagai berikut :

1. Waktu Proses

Waktu proses adalah waktu yang diperlukan untuk pengerjaan tiap operasi dalam tiap job, termasuk didalamnya waktu set up dan waktu persiapan.

2. Waktu Baku

Waktu baku adalah waktu yang dibutuhkan pekerja dengan kemampuan rata-rata untuk menyelesaikan pekerjaan secara normal.Waktu baku ini diperoleh melalui pengukuran waktu kerja dengan jam henti (Stop Watch)

3. Data Permintaan

Data permintaan adalah jumlah pemesanan atau permintaan dari konsumen pada masing-masing tipe job. Data permintaan ini merupakan data sekunder yang diperoleh dari perusahaan untuk permintaan tiap-tiap job pengerjaan, data ini diperlukan untuk menghitung total pengerjaan waktu untuk masing-masing job.

4. Data waktu pengerjaan job

Data ini merupakan pengolahan dari data waktu baku dan data permintaan.

\section{Metode Pengumpulan Data}

a. Data Primer

Data primer adalah data yang diukur pada saat penelitian lapangan oleh peneliti pada obyek penelitian, dimana data diperoleh secara langsung di perusahaan yang sedang diteliti.

b. Data Sekunder

Data sekunder adalah data yang diperoleh peneliti dengan melakukan pengumpulan data yang telah ada di perusahaan (dokumen perusahaan) tanpa ada perhitungan terlebih dahulu.

\section{Flowchart Metode NEH}

Pengolahan data yang pertama menggunakan Metode NEH (Nawaz, Enscore and Smith) sebagai acuan usulan pergantian penjadwalan produksi. Flowchart pengggunaan metode NEH dapat dilihat pada Gambar 2. 


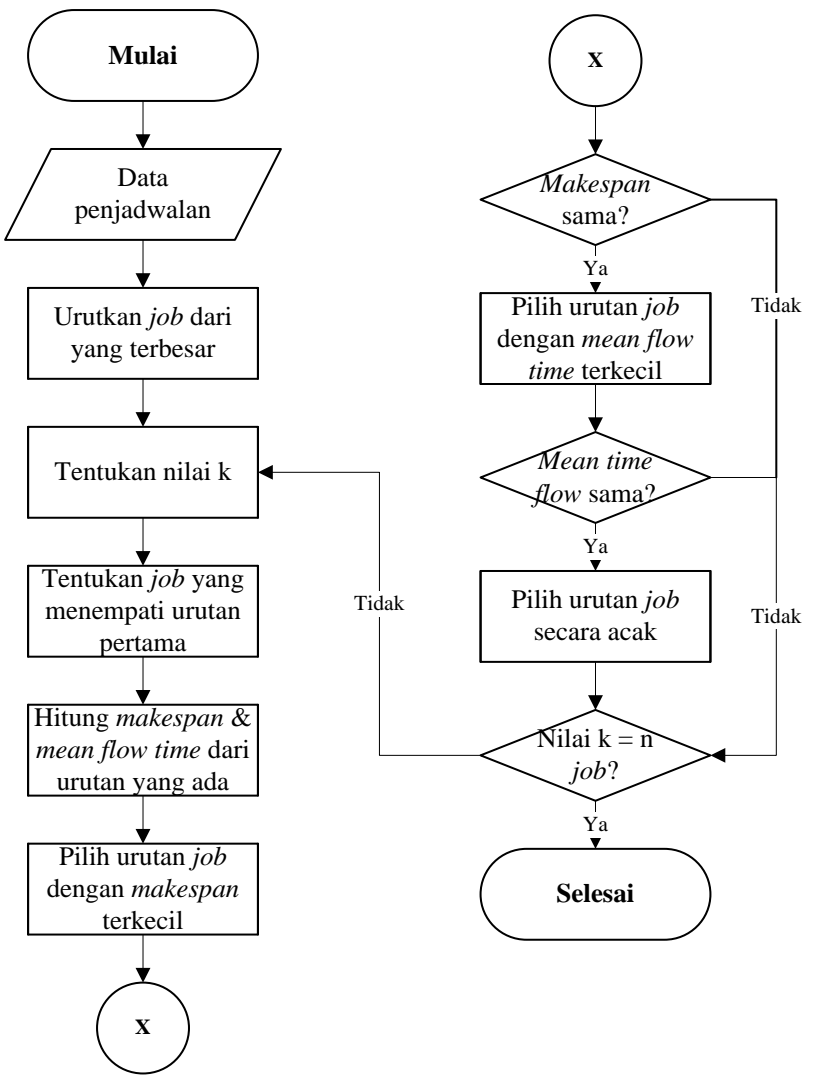

Gambar 2. Flowchart Metode NEH

\section{HASIL DAN PEMBAHASAN Makespan Riil Perusahaan}

Dari data yang telah diamati di perusahaan mengenai banyak job yang ada di perusahaan, waktu siklus, ketersediaan mesin, dan lainnya maka didapatkan hasil makespan perusahaan pada bulan Juli 2017. Waktu keseluruhan yang diperlukan perusahaan untuk menyelesaikan job pada bulan Juli 2017 adalah selama 960,87 jam atau selama 45,75 hari. Tabel dapat dilihat dibawah ini. Tabel Proses mencari makespan dan tabel makespan perusahaan dapat dilihat pada Tabel 1 dan 2.

Sehingga dari hasil perhitungan makespan dari produksi perusahaan pada bulan Juli 2017 totalnya selama 960,87 jam untuk memenuhi seluruh permintaan dari perusahaan.

Adapula usulan penjadwalan produksi yang dilakukan untuk meminimasi makespan. Hasil perhitungan yang dilakukan menggunakan metode NEH (Nawaz, Enscore, dan Ham) untuk meminimasi makespan, dapat dilihat pada Tabel 3 dan Tabel 4.

Tabel 1. Urutan Proses Job Perusahaan

\begin{tabular}{ccccccc}
\hline \multirow{2}{*}{ Job } & \multicolumn{4}{c}{ Mesin Blending } & \multicolumn{3}{c}{ Mesin Mixing } \\
\cline { 2 - 6 } & Kode & Start (Jam) & End (Jam) & Kode & Start (Jam) & End (Jam) \\
\hline 1 & B1 & 0 & 221,704 & M1 & 221,704 & 286,23 \\
2 & B2 & 0 & 163,018 & M2 & 163,016 & 201,252 \\
3 & B3 & 0 & 312,994 & M3 & 312,994 & 386,404 \\
4 & B4 & 0 & 228,225 & M4 & 228,225 & 281,753 \\
5 & B2 & 163,018 & 326,034 & M2 & 326,034 & 364,269 \\
6 & B1 & 221,704 & 443,408 & M4 & 443,408 & 495,407 \\
7 & B4 & 228,225 & 603,165 & M2 & 603,165 & 691,105 \\
8 & B3 & 312,994 & 443,408 & M1 & 443,408 & 473,996 \\
9 & B2 & 326,034 & 547,738 & M4 & 547,738 & 599,737 \\
10 & B1 & 443,408 & 635,769 & M3 & 635,769 & 680,886 \\
11 & B3 & 443,408 & 691,195 & M1 & 691,195 & 749,312 \\
12 & B2 & 547,738 & 743,359 & M4 & 743,359 & 789,241 \\
13 & B4 & 603,165 & 877,035 & M3 & 877,035 & 941,269 \\
14 & B1 & 635,769 & 798,787 & M2 & 798,787 & 837,022 \\
15 & B3 & 691,195 & 909,639 & M1 & 909,639 & 960,874 \\
\hline
\end{tabular}

Tabel 2. Makespan Produksi Perusahaan

\begin{tabular}{ccc}
\hline Periode & Urutan Job Penjadwalan & $\begin{array}{c}\text { Makespan Perusahaan } \\
(\mathrm{Jam})\end{array}$ \\
\hline Juli 2017 & $1-2-3-4-5-6-7-8-9-10-11-12-13-14-15$ & 960,87 \\
\hline
\end{tabular}


Usulan Penjadwalan Produksi Benang Menggunakan Metode NEH dan Metode Algoritma Johnson untuk Meminimasi Waktu Produksi di PT. Laksana Kurnia Mandiri Sejati

Silvi Ariyanti, Adianto dan Ricky Miharja

Tabel 3. Urutan Proses Job Metode NEH

\begin{tabular}{ccccccc}
\hline & \multicolumn{3}{c}{ Mesin Blending } & \multicolumn{3}{c}{ Mesin Mixing } \\
\cline { 2 - 7 } & Kode & $\begin{array}{c}\text { Start } \\
(\text { Jam })\end{array}$ & End (Jam) & Kode & $\begin{array}{c}\text { Start } \\
(\text { Jam })\end{array}$ & End (Jam) \\
\hline 7 & B1 & 0 & 374,94 & M1 & 374,94 & 462,88 \\
3 & B2 & 0 & 312,99 & M2 & 312,99 & 386,41 \\
13 & B3 & 0 & 273,87 & M3 & 273,87 & 338,1 \\
11 & B4 & 0 & 247,79 & M4 & 247,79 & 305,9 \\
1 & B4 & 247,9 & 469,49 & M4 & 469,49 & 534,02 \\
4 & B3 & 273,87 & 502,1 & M3 & 502,1 & 555,62 \\
6 & B2 & 312,99 & 534,7 & M2 & 534,7 & 586,7 \\
9 & B1 & 374,94 & 596,64 & M1 & 596,64 & 648,64 \\
15 & B4 & 469,49 & 687,94 & M4 & 687,94 & 739,17 \\
12 & B3 & 502,1 & 697,72 & M3 & 697,72 & 743,6 \\
10 & B2 & 534,7 & 727,06 & M2 & 727,06 & 772,18 \\
2 & B1 & 596,64 & 759,66 & M1 & 759,66 & 797,9 \\
5 & B4 & 687,94 & 850,95 & M4 & 850,95 & 777,41 \\
14 & B3 & 697,72 & 860,73 & M3 & 860,73 & 898,97 \\
8 & B2 & 727,06 & 857,47 & M2 & 857,47 & 888,06 \\
\hline
\end{tabular}

Tabel 4. Makespan Metode Usulan Metode NEH

\begin{tabular}{ccc}
\hline \multirow{2}{*}{ Periode } & Urutan Job Penjadwalan & $\begin{array}{c}\text { Makespan Perusahaan } \\
\text { (Jam) }\end{array}$ \\
\hline Juli 2017 & $7-3-13-11-1-4-6-9-15-12-10-2-5-14-8$ & 898,97 \\
\hline
\end{tabular}

Makespan Penjadwalan Usulan dengan Metode NEH

Dari hasil perhitungan diatas dengan menggunakan metode NEH didapatkan urutan produksi yang berbeda dengan perusahaan, urutan job nya menjadi 7-3-13-11-1-4-6-9-1512-10-2-5-14-8 , dengan urutan tersebut maka diperoleh makespan selama 898,97 jam untuk menyelesaikan job pada bulan Juli 2017.

\section{Makespan Penjadwalan Usulan dengan Algoritma Johnson}

Selain metode NEH sebagai metode usulan, adapula metode yang digunakan untuk mengurangi makespan perusahaan sebagai alternative, yaitu menggunakan Algoritma Johnson. Hasil perhitungan metode Algoritma Johnson dapat dilihat pada Tabel 5 dan Tabel 6.

Dari Tabel 6s, diketahui bahwa urutan proses nya menjadi 7-3-1-13-11-4-9-6-15-1210-14-5-2-8 dengan menggunakan algoritma
Johnson dan makespan nya menjadi 898,97 jam untuk menyelesaikan job pada bulan Juli 2017.

\section{Perbandingan dan Analisa Selisih Makespan Antar Metode}

Berikut ini merupakan selisih perbandingan antara waktu perusahaan dengan metode usulan untuk mengetahui penggunaan dengan waktu yang efektif. Selisih perbandingan dapat dilihat pada Tabel 7.

Dari hasil perhitungan yang telah di peroleh menggunakan kedua metode tersebut yaitu metode NEH (Nawaz, Enscore, dan Ham) dan Algoritma Johnson adalah 898,97 jam dibandingkan makespan perusahaan yaitu selama 960,87 jam dengan selisih sebesar 61,9 jam atau sebesar $6,44 \%$. Sehingga metode yang diusulkan lebih efektif dibandingkan metode yang digunakan oleh perusahaan. 
Tabel 5. Urutan Proses Job Algoritma Johnson

\begin{tabular}{ccccccc}
\hline \multirow{2}{*}{ Job } & \multicolumn{3}{c}{ Mesin Blending } & \multicolumn{3}{c}{ Mesin Mixing } \\
\cline { 2 - 7 } & Kode & Start (Jam) & End (Jam) & Kode & Start (Jam) & End (Jam) \\
\hline 7 & B1 & 0 & 374,94 & M1 & 374,94 & 462,88 \\
3 & B2 & 0 & 312,994 & M2 & 312,994 & 386,405 \\
1 & B3 & 0 & 221,704 & M3 & 221,704 & 286,23 \\
13 & B4 & 0 & 273,87 & M4 & 273,87 & 338,104 \\
11 & B3 & 221,704 & 469,404 & M3 & 469,404 & 527,5 \\
4 & B4 & 273,87 & 502,095 & M4 & 502,095 & 555,624 \\
9 & B2 & 312,994 & 534,698 & M2 & 534,698 & 586,697 \\
6 & B1 & 374,94 & 596,644 & M1 & 596,644 & 648,643 \\
15 & B3 & 469,404 & 687,848 & M3 & 687,848 & 739,083 \\
12 & B4 & 502,095 & 697,716 & M4 & 697,716 & 743,598 \\
10 & B2 & 534,698 & 727,059 & M2 & 727,059 & 772,176 \\
14 & B1 & 596,644 & 759,662 & M1 & 759,662 & 797,897 \\
5 & B3 & 687,848 & 850,866 & M3 & 850,866 & 889,101 \\
2 & B4 & 697,716 & 860,734 & M4 & 860,734 & 898,969 \\
8 & B2 & 727,059 & 857,473 & M2 & 857,473 & 888,061 \\
\hline
\end{tabular}

Tabel 6. Makespan Metode Usulan Algoritma Johnson

\begin{tabular}{ccc}
\hline \multirow{2}{*}{ Periode } & Urutan Job Penjadwalan & $\begin{array}{c}\text { Makespan Perusahaan } \\
(\mathrm{Jam})\end{array}$ \\
\hline Juli 2017 & $7-3-1-13-11-4-9-6-15-12-10-14-5-2-8$ & 898,97 \\
\hline
\end{tabular}

Tabel 7. Perbandingan Selisih Makespan

\begin{tabular}{cccccc}
\hline Periode & $\begin{array}{c}\text { Perusahaan } \\
(\text { Jam })\end{array}$ & $\begin{array}{c}\text { Metode NEH (Nawaz, } \\
\text { Enscore, Ham }) \\
(\text { Jam })\end{array}$ & $\begin{array}{c}\text { Metode Algirtma } \\
\text { Johnson } \\
(\text { Jam })\end{array}$ & $\begin{array}{c}\text { Selisih } \\
(\text { Jam })\end{array}$ & $\begin{array}{c}\text { Persentase } \\
(\%)\end{array}$ \\
\hline Juli & 960,87 & 898,97 & 898,97 & 61,9 & 6,44 \\
\hline
\end{tabular}

Dengan begitu perusahaan dapat memilih salah satu dari metode yang digunakan, guna mempersingkat waktu makespan. Pemilihan metode dapat disesuaikan dengan jumlah permintaan konsumen dan ketersediaan mesin yang ada. Adapula yang harus diperhatikan selain daripada penjadwalan produksi, yaitu mengenai ketersediaan bahan baku, kondisi di lapangan, kondisi mesin dan lainnya guna untuk memperkecil waktu siklus setiap produk. Serta pengawasan yang lebih ketat dan manajemen perusahaan dalam program peningkatan motivasi kerja 171 pada para pekerja agar bisa meminimasi waktu idle (menganggur) yang menyebabkan penumpukan job. Karena penjadwalan produksi tidak hanya mementingkan bagaimana job itu di selesaikan dengan waktu yang cepat,tetapi harus tetap memperhatikan mutu dan kualitas produk.

\section{Perbandingan Lateness Antar Metode}

Pada setiap job pasti memiliki batas waktu maksimal pengiriman yang telah ditentukan oleh kedua belah pihak yaitu konsumen dan produsen. Pada perusahaan PT. Laksana Kurnia memiliki deadline yang sama pada setiap job nya yaitu perusahaan memiliki due date selama 35 hari kerja atau selama 735 jam pada setiap job-nya. Perbandingan Lateness antar metode dapat dilihat pada Tabel 8. 
Usulan Penjadwalan Produksi Benang Menggunakan Metode NEH dan Metode Algoritma Johnson untuk Meminimasi Waktu Produksi di PT. Laksana Kurnia Mandiri Sejati

Silvi Ariyanti, Adianto dan Ricky Miharja

Tabel 8. Perbandingan Lateness Antar Metode

\begin{tabular}{|c|c|c|c|c|c|c|c|}
\hline \multirow[t]{2}{*}{$J o b$} & \multirow{2}{*}{$\begin{array}{l}\text { Due } \\
\text { Date } \\
\text { (Jam) }\end{array}$} & \multicolumn{2}{|c|}{$\begin{array}{c}\text { Perusahaan } \\
(\mathrm{Jam})\end{array}$} & \multicolumn{2}{|c|}{$\begin{array}{c}\begin{array}{c}\text { Metode NEH } \\
\text { (Jam) }\end{array} \\
\end{array}$} & \multicolumn{2}{|c|}{$\begin{array}{c}\text { Algoritma Johnson } \\
(\mathrm{Jam})\end{array}$} \\
\hline & & Completion & Lateness & Completion & Lateness & Completion & Lateness \\
\hline 1 & 735 & 286,23 & 0 & 534,02 & 0 & 286,23 & 0 \\
\hline 2 & 735 & 201,252 & 0 & 797,9 & 62,9 & 898,969 & 163,969 \\
\hline 3 & 735 & 386,404 & 0 & 386,41 & 0 & 386,405 & 0 \\
\hline 4 & 735 & 281,753 & 0 & 555,62 & 0 & 555,624 & 0 \\
\hline 5 & 735 & 364,269 & 0 & 777,41 & 42,41 & 889,101 & 154,101 \\
\hline 6 & 735 & 495,407 & 0 & 586,7 & 0 & 648,643 & 0 \\
\hline 7 & 735 & 691,105 & 0 & 462,88 & 0 & 462,88 & 0 \\
\hline 8 & 735 & 473,996 & 0 & 888,06 & 153,06 & 888,061 & 153,061 \\
\hline 9 & 735 & 599,737 & 0 & 648,64 & 0 & 586,697 & 0 \\
\hline 10 & 735 & 680,886 & 0 & 772,18 & 37,18 & 772,176 & 37,176 \\
\hline 11 & 735 & 749,312 & 14,312 & 305,9 & 0 & 527,5 & 0 \\
\hline 12 & 735 & 789,241 & 54,241 & 743,6 & 8,6 & 743,598 & 8,598 \\
\hline 13 & 735 & 941,269 & 206,269 & 338,1 & 0 & 338,104 & 0 \\
\hline 14 & 735 & 837,022 & 102,022 & $\mathbf{8 9 8 , 9 7}$ & 163,97 & 797,897 & 62,897 \\
\hline 15 & 735 & 960,874 & 225,874 & 739,17 & 4,17 & 739,083 & 4,083 \\
\hline & & Total & 602,72 & Total & 472,29 & Total & 583,88 \\
\hline
\end{tabular}

Dari Tabel 8 dapat disimpulkan bahwa metode NEH merupakan metode yang paling efektif untuk digunakan perusahaan karena memiliki nilai lateness yang paling kecil yaitu sebesar 472,29 jam dibandingkan dengan metode perusahaan yaitu sebesar 602,72 jam maupun Algoritma Johnson yang sebesar 583,88 jam.

\section{KESIMPULAN}

Dari hasil pengolahan yang dilakukan untuk job pada bulan Juli 2017 dapat diambil kesimpulan bahwa metode NEH dan Algoritma Johnson memiliki makespan yang sama dengan total makespan 898,97 jam. Dengan begitu selisih waktu dengan perusahaan yakni selama 61,9 jam atau selama 2 hari 20 jam kerja atau memperkecil sebesar $6,44 \%$ dari makespan perusahaan. Selain itu, metode NEH memiliki nilai nilai lateness yang terkecil yaitu sebesar 472,29 jam dibandingkan metode lain yang memiliki nilai lateness yang lebih tinggi. Perusahaan dapat menerapkan metode NEH sebagai metode penjadwalan untuk memperkecil makespan, karena memiliki nilai lateness yang paling kecil. Urutan penjadwalan yang dapat diterapkan perusahaan berdasarkan hasil perhitungan dengan metode NEH adalah 7-3-13-11-1-4-6-9-15-12-10-2-5-14-8. Selain itu, perusahaan juga harus mempertimbangkan hal-hal yang membuat waktu siklus produk menjadi besar serta terus menjaga kondisi mesin tetap baik untuk menjaga kualitas benang.

\section{DAFTAR PUSTAKA}

[1] Ginting, Rosnani, 2009."Penjadwalan Mesin”, Edisi I, Graha Ilmu, Yogyakarta.

[2] Herjanto,eddy,1999, "Manajemen Produksi dan Operasi”, PT. Gramedia Widiasarana Indonesia,Jakarta.

[3] Kusuma, Hendra, 2002, "Perencanaan dan Pengendalian Produksi”,Penerbit Andi, Yogyakarta.

[4] Nasution, H.Arman,1999, "Perencanaan dan Pengendalian Produksi”,PT.Guna Widya, Jakarta.

[5] Pinedo, M.,1996. Scheduling theory, algoritms and systems, New Jersey, United States of America: Prentice-Hall. 